\title{
PEP-1-GRX-1 Modulates Matrix Metalloproteinase-13 and Nitric Oxide Expression of Human Articular Chondrocytes
}

\author{
Hyun Sook Hwang ${ }^{a, b}$ In Young Parka Soo Young Choic Hyun Ah Kimª,b \\ aDivision of rheumatology, Department of Internal Medicine, Hallym University Sacred Heart Hospital, \\ Kyunggi, 'Institute for Skeletal Aging, Hallym University, Chuncheon, 'Department of Biomedical \\ Science and Research Institute of Bioscience and Biotechnology, Hallym University, Chuncheon, Korea
}

\section{Key Words}

Glutaredoxin-1 - Protein transduction domain - Matrix metalloproteinase - Chondrocyte • Osteoarthritis.

\begin{abstract}
Background: The protein transduction domain (PTD) enables therapeutic proteins to directly penetrate the membranes of cells and tissues, and has been increasingly utilized. Glutaredoxin-1 (GRX-1) is an endogenous antioxidant enzyme involved in the cellular redox homeostasis system. In this study, we investigated whether PEP-1-GRX-1, a fusion protein of GRX-1 and PEP-1 peptide, a PTD, could suppress catabolic responses in primary human articular chondrocytes and a mouse carrageenan-induced paw edema model. Methods: Human articular chondrocytes were isolated enzymatically from articular cartilage and cultured in a monolayer. The transduction efficiency of PEP-1-GRX-1 into articular chondrocytes was measured by western blot and immunohistochemistry. The effects of PEP-1-GRX-1 on matrix metalloproteinases (MMPs) and catabolic factor expression in interleukin (IL)-1 $\beta$ - and lipopolysaccharide (LPS)-treated chondrocytes were analyzed by real-time quantitative reverse transcription-polymerase chain reaction and western blot. The effect of PEP-1-GRX1 on the mitogen-activated protein kinase (MAPK) and nuclear factor kappa-light chain-enhancer of activated $B$ cells (NF-KB) signaling pathway were also analyzed by western blot. Finally, the inhibitory effect of PEP-1-GRX-1 on MMP-13 production was measured in vivo in a mouse carrageenan-induced paw edema model. Results: PEP-1-GRX-1 significantly penetrated into human chondrocytes and mouse cartilage, whereas GRX-1 did not. PEP-1-GRX-1 significantly suppressed MMP-13 expression and nitric oxide (NO) production in LPS-stimulated chondrocytes, and NO production in IL-1 $\beta$-stimulated chondrocytes, compared with GRX1. In addition, PEP-1-GRX-1 decreased IL-1 $\beta$ - and LPS-induced activation of MAPK and NF$\mathrm{KB}$. In the mouse model of carrageenan-induced paw edema, PEP-1-GRX-1 significantly suppressed carrageenan-induced MMP-13 production as well as paw edema. Conclusion: These results demonstrate that PEP-1-GRX-1 can be transduced efficiently in vitro and in vivo

H. S. Hwang and I. Y. Park contributed equally to this work.


into human chondrocytes and mouse cartilage tissue and downregulate catabolic responses in chondrocytes by inhibiting the MAPK and NF-KB pathway. PEP-1-GRX-1 thus has the potential to reduce catabolic responses in chondrocytes and cartilage.

\section{Introduction}

Osteoarthritis $(\mathrm{OA})$ is a common joint disorder characterized by reduced chondrocyte cellularity, cartilage degeneration, and joint dysfunction [1]. Multiple factors that disturb cartilage homeostasis and induce imbalance of anabolic and catabolic factors are involved in OA progression. However, since the pathogenic mechanisms during OA progression still remain largely unclear, the molecular events associated with $\mathrm{OA}$ development have been investigated to pursue novel therapeutic targets for the prevention and treatment of this disease [2].

Gene therapy using adenoviral and lentiviral vectors has been a useful strategy to deliver specific target molecules into articular cartilage [3-5]. However, the efficacy of gene delivery, duration of gene expression, and toxicity have remained as major limitations of this technique $[6,7]$. Previously, it was reported that the basic domain of the human immunodeficiency virus type 1 (HIV-1) transactivator of transcription (Tat) protein possesses the ability to traverse biological membranes efficiently in a process termed 'protein transduction' [8, 9]. The transduction domain is a region rich in positively charged amino acids and interacts with negatively charged phospholipids in the mammalian plasma membrane in a receptoror transporter-independent fashion [10]. In addition, a variety of protein transduction domains (PTDs), including the third alpha-helix of Antennapedia homeodomain protein, VP22 protein from herpes simplex virus, the poly-arginine peptide, calcitonin-derived peptide, and Transportan, have attracted substantial interest in protein therapeutics [11]. In particular, PEP-1 peptide, an amphipathic peptide consisting of a hydrophobic tryptophanrich sequence, a hydrophilic lysine-rich sequence, and a linker sequence, was developed for the application of therapeutic proteins without any chemical cross-linking or cloning [11]. It has been reported that PEP-1-mediated transduction was used for the delivery of biologically active molecules, including proteins, antibodies, small interfering RNA, and peptide nucleic acid, into various cell lines. We previously reported that a fusion protein, consisting of a PEP-1 PTD peptide and the 12-kDa FK506-binding protein (FK506BP12), penetrated effectively into human chondrocytes and cartilage explant cultures, and inhibited the expression of catabolic factors in vitro and in vivo [12]. In addition, a fusion protein of superoxide dismutase (SOD) with Tat peptide, Tat-SOD, inhibited IL-1 $\beta$-induced nitric oxide (NO) production and inducible nitric oxide synthase (iNOS) expression in chondrocytes [13]. Thus, the transduction of proteins using PTD can be regarded as a potential new therapy for OA.

Increasing reactive oxygen species (ROS) and oxidative stress are well correlated with the pathogenesis of arthritis. ROS play crucial roles in the inhibition of cartilage matrix synthesis, induction of chondrocyte apoptosis, and breakdown of cartilage matrix [14]. Elevated oxidative stress index and ROS level and decreased antioxidant parameters were found in the serum of patients with OA [15-17]. Dietary vitamins and selenium increased the expression of antioxidants such as glutathione (GSH) and $\mathrm{Cu} / \mathrm{Zn}$ SOD and diminished the induction of OA in STR/1N mice [18], suggesting that a potent antioxidant might prevent OA. The glutaredoxin (GRX) system, one of the antioxidant systems in cells, consists of GRX, GSH, and NADPH-dependent glutathione reductase. GRX-1, a 12-kDa protein, is found mainly in the cytosol and also detected in the nucleus as well as the mitochondria; it functions as a hydrogen donor for ribonucleotide reductase in DNA synthesis [19].

In this study, we produced a fusion protein consisting of PEP-1 and GRX-1 and tested the transducing capacity of PEP-1-GRX-1 into a chondrocyte monolayer culture and mouse cartilage tissues. The effect of PEP-1-GRX-1 on LPS- and IL-1 $\beta$-stimulated catabolic factor expressions in human chondrocytes and a carrageenan-induced paw arthritis mouse model

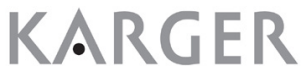




\section{Cellular Physiology Cell Physiol Biochem 2017;41:252-264

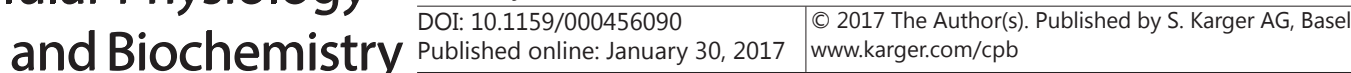

Hwang et al.: MMP-13 and NO Expression Modulated by PEP-GRX-1

was examined. The findings demonstrated the therapeutic potential of PEP-1-GRX-1 in terms of regulating the cartilage catabolic pathway of $\mathrm{OA}$.

\section{Materials and Methods}

\section{Materials}

Dulbecco's modified Eagle's medium (DMEM) and fetal bovine serum (FBS) were obtained from Welgene Inc. (Gyeongsan, Gyeongsangbukdo, South Korea). Fungizone (amphotericin B) and penicillin/ streptomycine were purchased from Gibco (Grand Island, NY, USA). Radioimmunoprecipitation assay (RIPA) lysis buffer and HEPES buffer were purchased from Biosesang (Seongnam, Kyunggi, South Korea). Antibodies to iNOS and $\beta$-actin were purchased from R\&D Systems (Minneapolis, MN, USA). Antibodies to phosphorylated-c-Jun N-terminal kinase (p-JNK), phosphorylated p38 (p-p38), phosphorylated

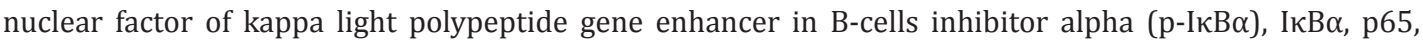
and phosphorylated extracellular signal-regulated kinase (p-ERK) were purchased from Cell Signaling Technology (Danvers, MA, USA). Horseradish peroxidase-conjugated secondary antibodies and anti-His rabbit antibody were obtained from Santa Cruz Biotechnology (Santa Cruz, CA, USA).

\section{Chondrocyte isolation and culture}

Human articular chondrocytes were obtained from the cartilage of patients with OA who underwent knee replacement surgery $[20,21]$. Patient diagnoses were determined using the criteria set forth by the American College of Rheumatology. The collection and use of human samples were reviewed and approved by the institutional review board of Hallym University Sacred Heart Hospital (Anyang, South Korea; approval number 2013-I022). All patients provided written informed consent. The cartilage slices were carefully dissected and incubated sequentially with protease from Streptomyces griseus, collagenase from Clostridium histolyticum, and hyaluronidase from bovine testes (Sigma-Aldrich, St. Louis, MO, USA). Chondrocytes were cultured in DMEM supplemented with 20\% FBS, $1 \%$ fungizone (150 units/mL), and penicillin/streptomycin $(50 \mathrm{mg} / \mathrm{mL})$ for $2-3 \mathrm{~d}$ and then maintained in DMEM containing $10 \%$ FBS.

\section{Transduction of PEP-1-GRX-1 fusion protein}

PEP-1-GRX-1 and GRX-1 were purified as previously described [12]. Briefly, Escherichia coli BL21 containing PEP-1-GRX-1 and GRX-1 expression vectors was cultured to an optical density of 0.6-1.0 at 600 $\mathrm{nm}$ and isopropyl- $\beta$-D-thiogalactoside $(0.5 \mathrm{mM})$ was added to the culture to induce the overexpression of PEP-1-GRX-1 and GRX-1. The cells were harvested by centrifugation and lysed by sonication on ice. PEP1-GRX-1 and GRX-1 in cell lysates were purified under conditions of binding (10 mM imidazole), washing (30 mM imidazole), and elution (200 mM imidazole) buffers using an $\mathrm{Ni}^{2+}$-nitrilotriacetic acid-Sepharose column. Purified proteins were desalted using PD-10 desalting column chromatography (GE Healthcare, Piscataway, NJ, USA).

To examine the capacity of PEP-1-GRX-1 and GRX-1 to penetrate chondrocytes, chondrocytes were seeded onto a 60-mm culture dish at a density of $6 \times 10^{5}$ and exposed to PEP-1-GRX-1 $(0.2,0.5$, and $1 \mu \mathrm{M})$ or GRX-1 $(1 \mu \mathrm{M})$ for $2 \mathrm{~h}$. The cells were incubated with trypsin-ethylenediaminetetraacetic acid for $1 \mathrm{~h}$ to remove membrane-bound proteins, washed three times with phosphate-buffered saline (PBS), and then harvested by centrifugation. The harvested cells were subjected to immunoblot analysis.

\section{Assay for PEP-1-GRX-1 and GRX-1}

GRX-1 activity was assessed in a coupled assay with glutathione reductase. Briefly, enzyme solution or cell lysates from chondrocytes were preincubated with assay buffer, supplemented with $0.4 \mathrm{mM}$ NADPH, 1 $\mathrm{mM} \mathrm{GSH}$, and $6 \mu \mathrm{g} / \mathrm{ml}$ glutathione reductase from Bakers yeast at room temperature. $0.7 \mathrm{mM}$ 2-hydroxyethyl disulfide as substrate was added to assay solution and the absorbance was measured at $340 \mathrm{~nm}$ for one minute. 1 unit of GRX-1 was defined as $\mu$ mole NADPH reduced per minute.

Immunoblot analysis

Chondrocytes were lysed in RIPA buffer (150 mM NaCl, 1\% Triton X-100, 1\% sodium deoxycholate, $0.1 \%$ SDS, $50 \mathrm{mM}$ Tris-HCl, pH7.5, and $2 \mathrm{mM}$ EDTA). Cell lysates were centrifuged at 13,000 rpm and the 


\section{Cellular Physiology Cell Physiol Biochem 2017;41:252-264

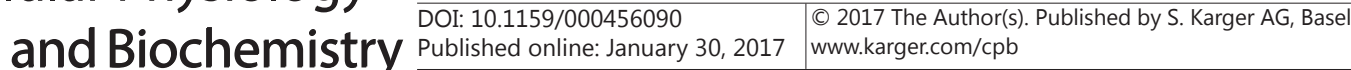

Hwang et al.: MMP-13 and NO Expression Modulated by PEP-GRX-1

protein concentration of each sample was measured by the bicinchoninic acid assay. Equal amounts of protein samples were subjected to $10 \%$ sodium dodecyl sulfate polyacrylamide gel electrophoresis (SDSPAGE) and transferred to a polyvinylidene difluoride membrane (Bio-Rad Laboratories, Hercules, CA, USA). The membrane was blocked with 5\% nonfat milk and incubated with primary antibody and secondary antibody. Signals were detected using an enhanced chemiluminescence kit (Santa Cruz Biotechnology).

Quantitative real-time reverse transcription-polymerase chain reaction ( $q R T P C R$ )

Total RNA was isolated from chondrocytes using Trizol reagent (Invitrogen, Carlsbad, CA, USA). cDNA were generated using a reverse transcription reaction with Go Script (Promega, Madison, WI, USA) and oligo(dT) (Promega). Real-time PCR analysis was performed with a QuantiFast SYBR Green PCR Kit (Qiagen, Hilden, Germany) using a StepOne Plus real-time PCR system (Applied Biosystems, Foster, CA, USA). The primer sequences of specific genes for real-time PCR were as follows: for iNOS, 5'-ACATTGATGAGAAGCTGTCC-3' (forward) and 5'-CAAAGGCTGTGAGTCCTGCA-3' (reverse); for MMP-13, 5'- AAGGACCCTGGAGCACTCATGTTT-3 (forward) and 5'-TGGCATCAAGGGATAAGGAAGGGT-3' (reverse); and for GAPDH, 5'-TGATGACATCAAGAAGGTGGTGAAG-3' (forward) and 5'-TCCTTGGAGGCCATGTGGGCCAT-3' (reverse).

Enzyme-linked immunosorbent assay (ELISA)

Chondrocytes were incubated with PEP-1-GRX-1 and GRX-1 for $2 \mathrm{~h}$, and were then simulated for $24 \mathrm{~h}$ with lipopolysaccharide (LPS) (Sigma-Aldrich). Twenty-four hours later, the culture medium was collected. For the experiment on joint tissues, mouse joint tissues frozen at $-70^{\circ} \mathrm{C}$ were ground carefully into powder using a chilled mortar and pestle. Once the grinding was complete, the sample was transferred into a microcentrifuge tube and homogenization buffer ( 2 volumes) containing protease inhibitor (Sigma-Aldrich) was added to the tissue homogenate. After vortexing the tissue homogenates vigorously for 3-5 min three times, the supernatant was obtained by centrifugation at 13,000 rpm for $10 \mathrm{~min}$. MMP-13 protein in the medium samples and cartilage homogenates was quantified by ELISA using the Quantikine Human Pro MMP-13 Immunoassay kit, in accordance with the manufacturer's instructions (R\&D Systems).

Nitric oxide measurement

Nitric oxide (NO), a molecular mediator of inflammation, is oxidized to form nitrite. Nitrite concentration in the culture medium was measured using a Griess reagent kit (Promega), in accordance with the manufacturer's instructions. Briefly, culture medium was incubated with Griess reagent, consisting of $N$-(1-naphthyl)ethylenediamine and sulfanilic acid, for $30 \mathrm{~min}$ at room temperature and the absorbance of each sample was then measured at $548 \mathrm{~nm}$.

\section{Animal studies}

All animal experiments were performed in accordance with protocols approved by the Care and Use of Laboratory Animals Committee of the National Veterinary Research \& Quarantine Service of South Korea and the Hallym Medical Center Institutional Animal Care and Use Committee (HMC 2013-01-0530). To investigate the potential of PEP-1-GRX-1 to penetrate into mouse cartilage tissues, 16-week-old male C57BL/6N mice were purchased from Koatech (Pyeongtaek, Kyunggi, South Korea) and divided randomly into three groups ( $\mathrm{n}=3$ mice/group): PEP-1-GRX-1, GRX-1, and control. In these groups, PEP-1-GRX-1, GRX-1, and PBS, respectively, were injected intra-articularly into mice at a dose of $10 \mu \mathrm{g}$ protein $/ 10 \mu \mathrm{L}$ per mouse. Six hours later, the knee joints of the mice were fixed in $4 \%$ paraformaldehyde, decalcified in the histological decalcifying agent Calci-Clear Rapid (National Diagnostics, Atlanta, GA, USA), dehydrated, embedded in paraffin, and sectioned.

To examine the anti-inflammatory and anti-catabolic effects of PEP-1-GRX-1 in vivo, a carrageenaninduced paw edema model was employed. Mice were assigned randomly to five groups ( $\mathrm{n}=4 \mathrm{mice} / \mathrm{group})$ as follows: PBS, carrageenan, carrageenan+PEP-1-GRX-1 (0.2 mg/kg), carrageenan+PEP-1-GRX-1 (0.4 mg/ $\mathrm{kg})$, and carrageenan+GRX-1 (0.4 mg/kg). PEP-1-GRX-1, GRX-1, or PBS was injected subcutaneously into the plantar area of the right hindpaw. Two hours later, $40 \mu \mathrm{L}$ of $2.5 \%$ carrageenan (Sigma-Aldrich) was injected subcutaneously into the plantar area of the right hindpaw to induce inflammation. The mice were sacrificed $4 \mathrm{~d}$ later.

\section{KARGER}




\section{Immunohistochemical analysis}

Mouse knee joints injected intra-articularly with PEP-1-GRX-1, GRX-1, and PBS were fixed, de-calcified and embedded into paraffin to evaluate the penetration of PTD proteins into cartilage. Sections were deparaffinized with xylene, rehydrated, and incubated with $0.05 \%$ trypsin for $30 \mathrm{~min}$ at $37^{\circ} \mathrm{C}$. Then, sections were blocked with 1.5\% normal goat serum for $1 \mathrm{~h}$ and incubated with rabbit anti-His 804 polyclonal antibody (1:100 dilution; Santa Cruz Biotechnology) overnight at $4{ }^{\circ} \mathrm{C}$. The sections were then incubated with biotinylated goat anti-rabbit antibody (1:200 dilution; Vectastain Elite ABC Kit, Vector Laboratories, Burlingame, CA, USA) for $30 \mathrm{~min}$ at room temperature. After incubation, the sections were incubated with Vectastain $\mathrm{ABC}$ reagent for $30 \mathrm{~min}$, followed by exposure to 3,3'-diaminobenzidine (SK-4100; Vector Laboratories) for $8 \mathrm{~min}$. Methyl Green (Sigma-Aldrich) was used as a counterstain.

\section{Statistical analysis}

Data are expressed as mean \pm standard deviation (SD). The significance of differences between two groups was tested using the Mann-Whitney U-test (GraphPad Prism 6). For all of the analyses, a P value less than 0.05 was considered to indicate statistical significance.

\section{Results}

\section{Transduction of PEP-1-GRX-1 into human chondrocytes and mouse cartilage}

The detailed structures of PEP-1-GRX-1 and GRX-1 are shown in Fig. 1A. To determine whether PEP-1-GRX-1 can be transduced into chondrocytes, human chondrocytes were incubated with PEP-1-GRX-1 $(0.2,0.5$, and $1.0 \mu \mathrm{M})$ and GRX-1 $(1.0 \mu \mathrm{M})$ for $2 \mathrm{~h}$ and transduced PEP-1-GRX-1 was detected by western blot analysis. Our data showed that

Fig. 1. Transduction of PEP-1-GRX-1 into a monolayer of cultured human chondrocytes and mouse cartilage tissue. (A) Schematic structures of PEP-1-GRX-1 and GRX-1. PEP-1 PTD, a 21-residue peptide carrier, consists of hydrophobic Trp R (tryptophan-rich), spacer, and hydrophilic Lys R (lysine-rich) domains. His, the six-histidine motif, was used in the detection and purification of the two proteins. (B) Transduction of PEP-1-GRX-1 into human primary chondrocytes. Chondrocytes were incubated with PEP-1-GRX-1 $(0.2,0.5$, and $1 \mu \mathrm{M})$ and GRX$1(1 \mu \mathrm{M})$ for $2 \mathrm{~h}$ and then with trypsin-ethylenediaminetetraacetic acid for $1 \mathrm{~h}$. The levels of PEP-1-GRX-1 and GRX-1 in the cell lysates were measured by western blotting. (C) Activity assay of cell lysates from PEP-1-GRX-1- and GRX-1-transduced chondrocytes. Chondrocytes were incubated with PEP-1-GRX-1 $(1 \mu \mathrm{M})$ and GRX-1 $(1 \mu \mathrm{M})$ for $2 \mathrm{~h}$ and harvested. GRX-1 activity of each sample was measured using a coupled reaction with glutathione reductase. 1 unit $=\mu$ mole NADPH reduced per minute. (D) Transduction of PEP-1-GRX-1 into cartilage tissue of mouse joint. PEP-1-GRX-1, GRX-1, or phospha-

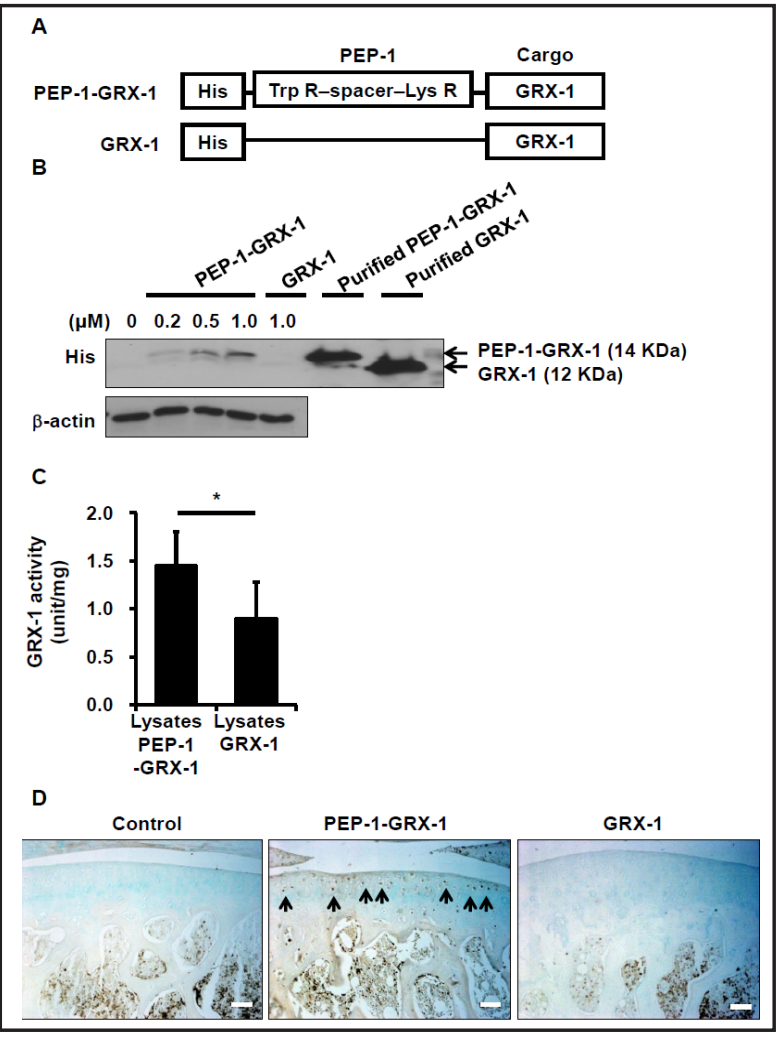
te-buffered saline was injected intra-atricularly at a dose of $10 \mu \mathrm{g}$ protein/10 $\mu \mathrm{L}$ per mouse into the knee joints of the mice. Six hours later, the knee joint tissues of the mice were harvested and immunostained with anti-His antibody. Immunohistochemistry data are representatives of two independent experiments using three different animals (n=3/group) (magnification; 200x). The arrows indicate the immune positive cells with His antibody. Scale bars $=100 \mu \mathrm{m}$. 
Fig. 2. PEP-1-GRX-1 suppresses lipopolysaccharide (LPS)-induced matrix metalloproteinase (MMP)-13 mRNA (A) and protein (B) levels. Chondrocytes were pretreated with PEP-1- GRX-1 (0.5 and $1 \mu \mathrm{M})$ or GRX-1 $(1 \mu \mathrm{M})$ for $2 \mathrm{~h}$ and exposed to LPS $(1 \mu \mathrm{g} / \mathrm{mL})$ for (A) 6 or (B) $24 \mathrm{~h}$. (A) mRNA level was measured using real-time quantitative PCR. (B) The level of MMP-13 released into culture media was inhibited by PEP-1-GRX-1 in a dose-dependent manner. MMP-13 protein levels in culture media was measured by MMP-13 enzyme-linked

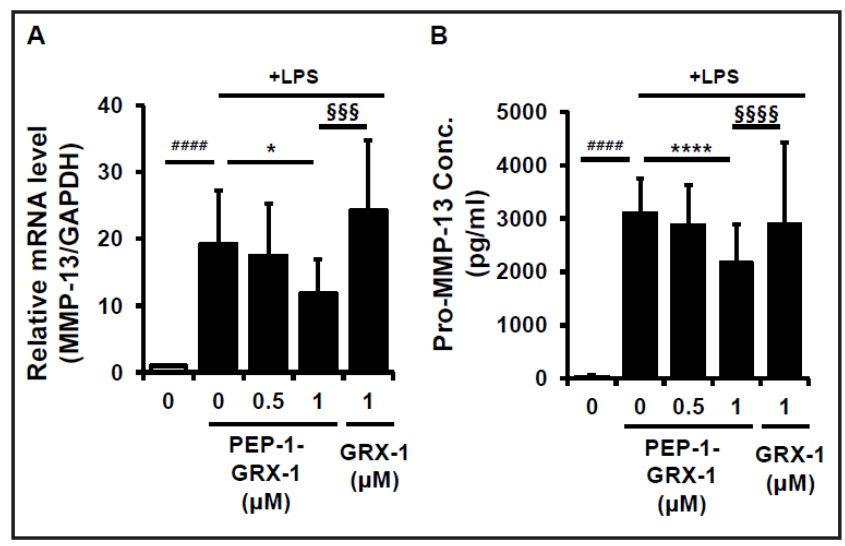
immunosorbent assay. Data are expressed as the mean \pm standard deviation of duplicate data from three different donors. \#\#\#\#P<0.001 vs. unstimulated control; ${ }^{*}, P<0.05$ and $* * * *, P<0.001$ vs. LPS-stimulated control; $\S \S \S, P<0.005$ and $\S \S \S \S, P<0.001$ vs. LPS+GRX-1-treated group.

PEP-1-GRX-1 was transduced significantly into primary chondrocytes in a dose-dependent manner, while the control GRX-1 was not (Fig. 1B). The functional activity of GRX-1 was measured using a coupled assay with glutathione reductase. Cell lysates from PEP-1-GRX-1 transduced chondrocytes had more than $60 \%$ higher activity of GRX-1 compared to GRX1 transduced chondrocytes (1.45 unit/mg vs 0.9 unit/mg) (Fig. 1C), revealing that PEP-1GRX-1 penetrated chondrocytes effectively and conferred higher GRX activity than GRX-1. Next, the transduction of PEP-1-GRX-1 into in vivo mouse cartilage tissues was evaluated. PEP-1-GRX-1, GRX-1, or PBS was injected intra-articularly into the knee joints of mice. Six hours later, the knee joint tissues of the mice were harvested and immunostained with an anti-His antibody. Our results revealed that PEP-1-GRX-1 penetrated significantly into the superficial zone of cartilage, while control GRX-1 did not (Fig. 1D). These results demonstrate that PEP-1-GRX-1, GRX-1 protein fused with PEP-1 peptide, has the capacity to penetrate chondrocytes and cartilage tissues significantly without any additional stimulus.

PEP-1-GRX-1 inhibited MMP-13 or nitric oxide production induced by LPS- or IL-1 $\beta$ treatment in chondrocytes

Chondrocytes produce NO and proinflammatory cytokines and activate catabolic processes in response to IL-1 $\beta$ and LPS, which are implicated in the pathogenesis of OA [2225]. We examined whether transduced PEP-1-GRX-1 has a regulatory function in chondrocyte catabolic signaling. Chondrocytes were incubated with PEP-1-GRX-1 for $2 \mathrm{~h}$, followed by incubation with LPS. PEP-1-GRX-1 (1 $\mu \mathrm{M})$ suppressed LPS-induced MMP-13 expression significantly at both the mRNA and protein levels (Fig. 2A and B). However, PEP-1-GRX-1 failed to suppress IL-1 $\beta$-induced MMP-13 expression (data not shown).

We also determined whether PEP-1-GRX-1 can mediate NO production, which is involved in cartilage degradation. Chondrocytes were pretreated with PEP-1-GRX-1 and GRX-1 for $2 \mathrm{~h}$ and stimulated with LPS and IL-1 $\beta$ for 6 and $24 \mathrm{~h}$. LPS and IL-1 $\beta$ induced the mRNA and protein expression of iNOS, which was suppressed significantly by PEP-1-GRX-1 $(1 \mu \mathrm{M})$ (Fig. 3A and B). However, GRX-1 failed to inhibit iNOS expression. In addition, PEP1-GRX-1 significantly decreased the nitrite accumulation stimulated by LPS and IL-1 $\beta$ in a concentration-dependent manner (Fig. 3C). On the other hand, PEP-1 peptide alone did not suppress iNOS or MMP-13 expression induced by IL-1 $\beta$ and LPS (Fig. 4A-D). Our findings show that PEP-1-GRX-1 significantly suppresses NO production in LPS- and IL-1 $\beta$-stimulated chondrocytes as well as MMP-13 expression in LPS-stimulated chondrocytes.

PEP-1-GRX-1 suppressed MAPK and NF- $\kappa B$ signaling activated by LPS and IL-1 $\beta$

Catabolic responses in articular cartilage are modulated via the MAPK and NF- $\kappa B$ signaling pathways [26]. We investigated the effect of PEP-1-GRX-1 on these signaling 
Fig. 3. PEP-1-GRX-1 suppresses lipopolysaccharide (LPS)- and interleukin (IL)-1 $\beta$-induced nitric oxide (NO) production in primary human chondrocytes. Chondrocytes were exposed to PEP-1-GRX-1 (0.5 and 1 $\mu \mathrm{M})$ for $2 \mathrm{~h}$ and then to LPS $(1 \mu \mathrm{g} / \mathrm{mL})$ and IL-1 $\beta$ ( $1 \mathrm{ng} / \mathrm{mL}$ ) for (A) 6 or (B) $24 \mathrm{~h}$. (B) The blot shown are representative of three or more independent experiments. (C) PEP-1-GRX-1 suppressed LPS- and IL-1 $\beta$ induced nitrite production, an indicator of nitric oxide synthase activity. Chondrocytes were exposed to PEP-1-GRX-1 (0.5 and 1 $\mu \mathrm{M})$ for $2 \mathrm{~h}$ and then to LPS $(1 \mu \mathrm{g} / \mathrm{mL})$ or IL$1 \beta(1 \mathrm{ng} / \mathrm{mL})$ for $24 \mathrm{~h}$. Nitrite concentration in culture medium was measured using a Griess reagent kit. Data are expressed as the mean \pm standard deviation of duplicate data from three different donors. \#\#\#\#, $P<$ 0.001 vs. unstimulated control; ${ }^{*}, P<0.05$, **, $P<0.01$, and ***, $P<0.005$ vs. LPS- or IL-1 $\beta$-stimulated control; $\S \S, P<0.01$ vs. LPS- or IL-1 $\beta-$ + GRX-1-treated group. ns, non-significant.

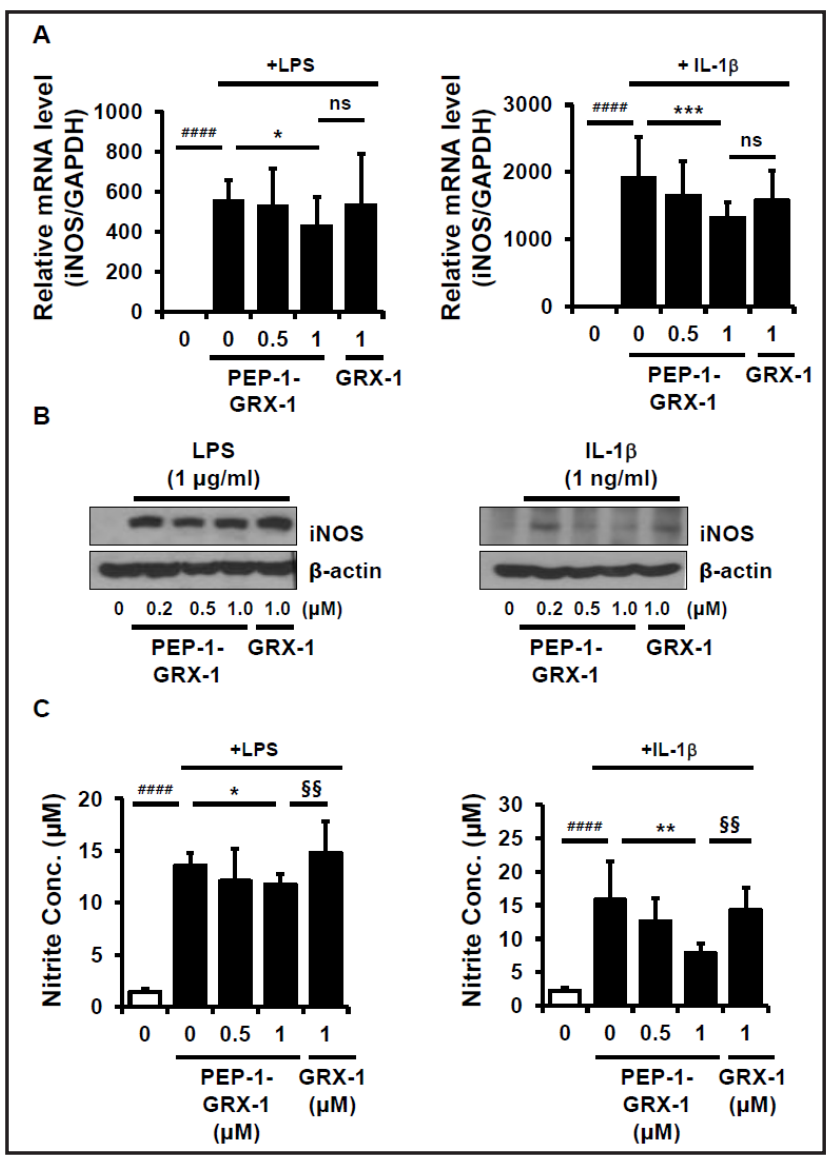

Fig. 4. PEP-1 alone did not inhibit lipopolysaccharide (LPS)and interleukin (IL)-1 $\beta$-induced iNOS and MMP-13 expression in primary human chondrocytes. Chondrocytes were pretreated with PEP-1 $(1 \mu \mathrm{M})$ for $2 \mathrm{~h}$ and exposed to LPS $(1 \mu \mathrm{g} / \mathrm{mL})$ or IL$1 \beta(1 \mathrm{ng} / \mathrm{mL})$ for (A) and (B) 6 or (C) and (D) $24 \mathrm{~h}$. The levels of iNOS and MMP-13 were measured using (A) and (B) real-time quantitative PCR, (C) Western blot assay, and (D) ELISA. Data are expressed as the mean \pm standard deviation of duplicate data from three different donors. ns, the difference between two groups is not significant.

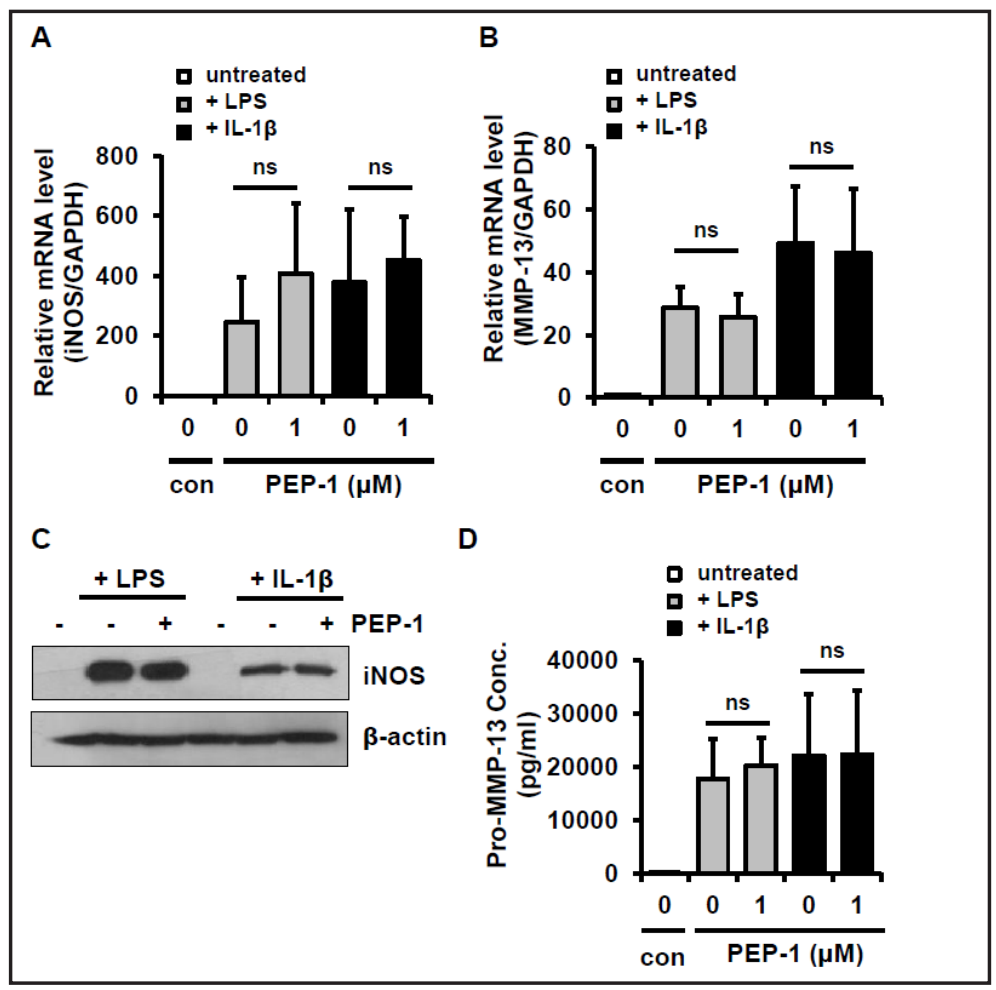

pathways. Chondrocytes were incubated with PEP-1-GRX-1 $(1 \mu \mathrm{M})$ for $2 \mathrm{~h}$ prior to incubation with LPS and IL- $1 \beta$ for $0,15,30$, and $60 \mathrm{~min}$. p38, JNK, and ERK1/2 were activated markedly 
Fig. 5. PEP-1-GRX-1 suppresses lipopolysaccharide (LPS)- and interleukin (IL)-1 $\beta$-induced mitogen-activated protein kinase and nuclear factor- $\kappa \mathrm{B}$ activation in primary chondrocytes. Chondrocytes were incubated with PEP-1-GRX-1 (1 $\mu \mathrm{M})$ for 2 $\mathrm{h}$ and then with (A) LPS (1 $\mu \mathrm{g}$ / $\mathrm{mL}$ ) or (B) IL-1 $\beta$ (1 ng/mL) for 15, 30, and $60 \mathrm{~min}$. p38, JNK and ERK1/2 phosphorylation and p65 nuclear translocation were measured by western blotting. $\beta$-actin and laminin served as loading controls. The blots shown are representative of three or more independent experiments using cartilage from three different donors. Cyto, cytosolic; Nuc, nuclear.

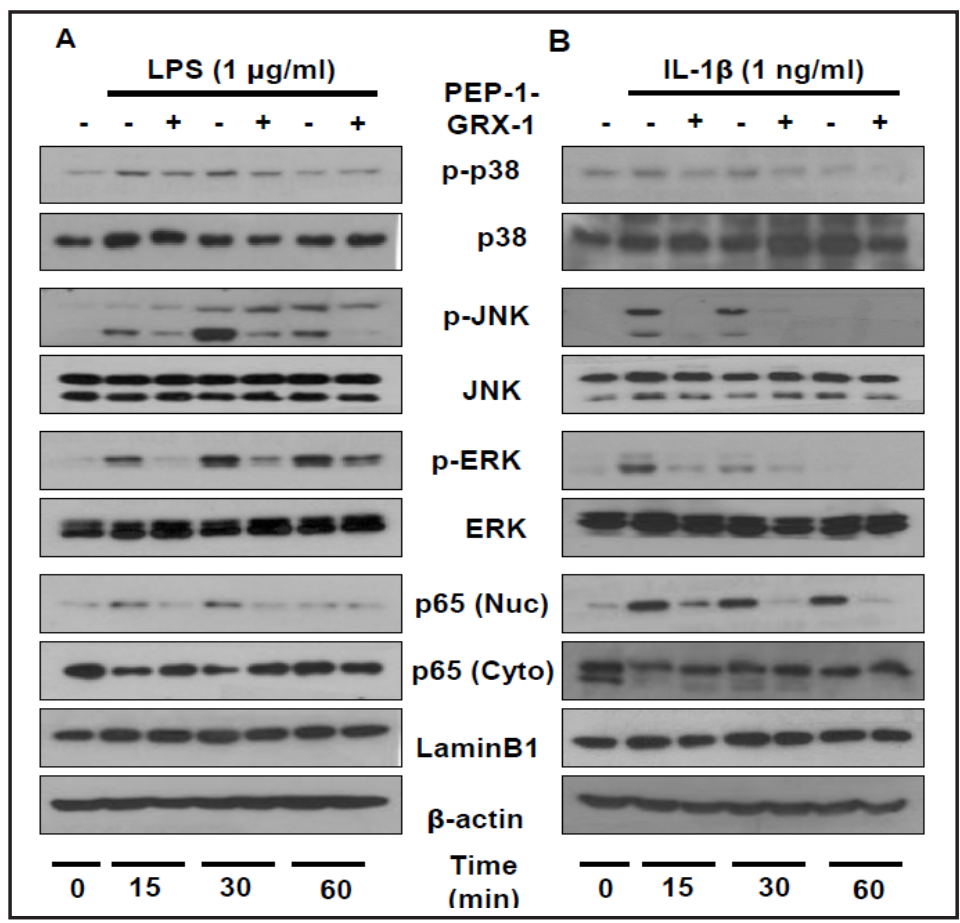

Fig. 6. PEP-1-GRX-1 inhibits paw edema and matrix metalloproteinase (MMP)-13 expression in a mouse carrageenan-induced paw edema model. (A) Experimental design to examine the anti-inflammatory activity of PEP-1-GRX-1 in a mouse paw edema model. (B) Carrageenan-induced edema of mouse hindpaw was suppressed by PEP-1GRX-1 (0.2 and $0.4 \mathrm{mg}$ / $\mathrm{kg}$ ), but not by GRX-1 $(0.4 \mathrm{mg} / \mathrm{kg})$. (C) Carrageenan-induced MMP-

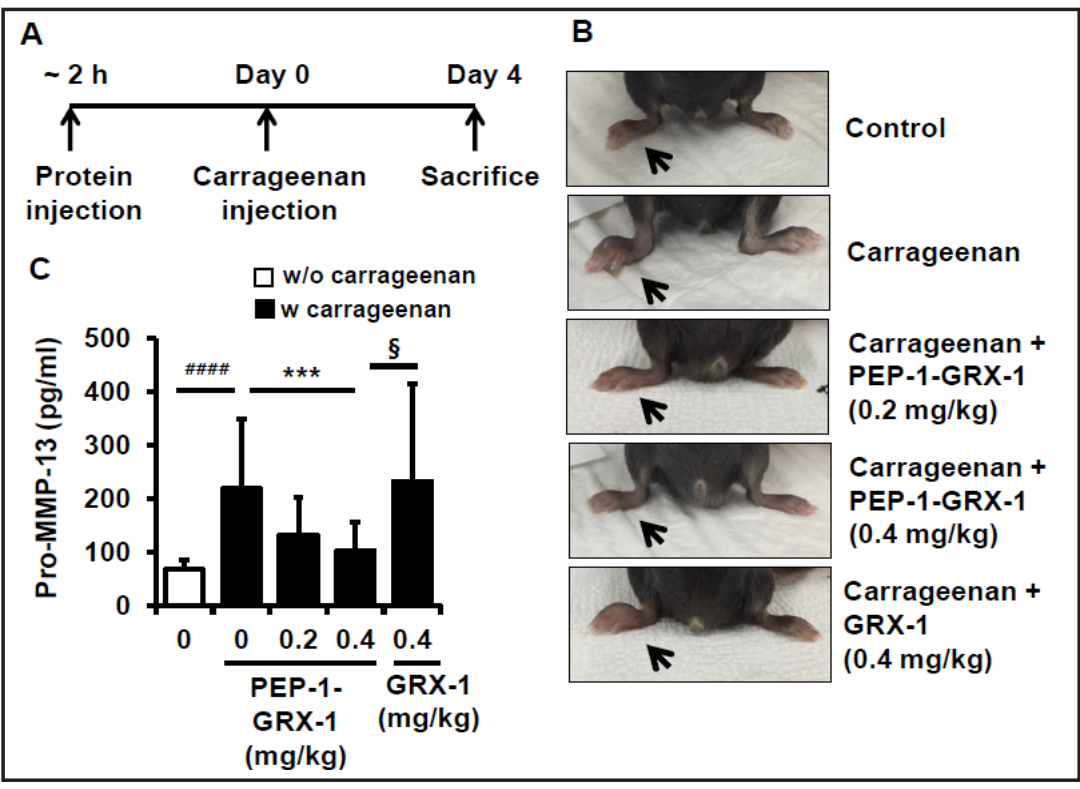
13 expression was inhibited by PEP-1-GRX-1. Joint tissue homogenates were prepared and MMP-13 level was measured using MMP-13 enzyme-linked immunosorbent assay kit. Data are expressed as the mean \pm standard deviation of duplicate data from four independent experiments using four different animals ( $\mathrm{n}=4$ / group). \#\#\#\#, $P<0.001$ vs. unstimulated control; ${ }^{* * *}, P<0.005$ vs. carrageenan-injected group; $§, P<0.05$ vs. carrageenan + GRX-1-injected group. w/o carrageenan, without carrageenan; w carrageenan, with carrageenan.

in the presence of LPS and IL-1 $\beta$. PEP-1-GRX-1 significantly inhibited the LPS- and IL-1 $\beta$ induced phosphorylation of p38, JNK, and ERK at 15 and 30 min (Fig. 5A and B). In addition, LPS- and IL-1 $\beta$-induced NF- $\kappa B$ nuclear translocation was suppressed by PEP-1-GRX-1 (Fig. $5 \mathrm{~A}$ and $\mathrm{B}$ ). These findings suggest that PEP-1-GRX-1 significantly inhibited LPS- and IL-1 $\beta$ induced activation of catabolic signaling in chondrocytes. 


\section{Cellular Physiology Cell Physiol Biochem 2017;41:252-264 \begin{tabular}{ll|l} 
DOI: 10.1159/000456090 & O 2017 The Author(s). Published by S. Karger AG, Basel \\
www.karger.com/cpb
\end{tabular} \\ Hwang et al.: MMP-13 and NO Expression Modulated by PEP-GRX-1}

PEP-1-GRX-1 inhibited MMP-13 production and edema in a mouse carrageenan-induced paw edema model

To determine the inhibitory effect of PEP-1-GRX-1 fusion protein in vivo, PEP-1-GRX-1 $(0.2$ or $0.4 \mathrm{mg} / \mathrm{kg})$ or GRX-1 $(0.4 \mathrm{mg} / \mathrm{kg})$ was injected $2 \mathrm{~h}$ prior to $2.5 \%$ carrageenan injection into the right hindpaw of mice to induce inflammation. The mice were sacrificed $4 \mathrm{~d}$ later (Fig. 6A). A representative photograph of the hindpaw reveals that it was significantly thicker in carrageenan-injected mice, whereas the hindpaw thickness of PEP-1-GRX-1-treated mice was decreased significantly compared with that of GRX-1-injected mice (Fig. 6B). In addition, the MMP-13 level in PEP-1-GRX-1-injected mice was reduced in a dose-dependent manner, whereas the control GRX-1 did not affect it (Fig. 6C). These results demonstrate that PEP-1GRX-1 significantly suppressed the catabolic response represented by MMP-13 in the mouse carrageenan-induced paw edema model.

\section{Discussion}

In this study, we demonstrated that PEP-1-GRX-1, a fusion protein consisting of PEP1 peptide and GRX-1, penetrated efficiently into human chondrocytes and mouse articular cartilage tissue compared with GRX-1.PEP-1-GRX-1 significantly downregulated LPS-induced MMP-13 expression as well as LPS- and IL-1 $\beta$-stimulated NO production in chondrocytes through the inhibition of MAPK and NF- $\mathrm{kB}$ activation. In addition, our mouse carrageenaninduced arthritis model data show that PEP-1-GRX-1 suppressed carrageenan-induced MMP-13 production and paw edema.

Previous studies demonstrated that ROS play an important role in a variety of inflammatory responses, including cytokine induction, recruitment of white blood cells to sites of injury, and glutathionylation of proteins, including actin, glyceraldehyde 3-phosphate dehydrogenase, c-Jun, and NF- $\kappa B$ [27]. The glutaredoxin (GRX) system, one of the defense systems in cells, consists of GRX, glutathione (GSH), and NADPH-dependent glutathione reductase. The expression of GRX, which is responsible for the deglutathionylation process together with GSH, is induced by ROS and ROS-induced cytokines, such as IL-4, -6, -13, tumor necrosis factor- $\alpha$ (TNF- $\alpha$ ), and interferon- $\gamma$ [28-30]. Human cells contain the three members of the glutaredoxins (GRXs): the cytosolic GRX-1 and two mitochondrial members, GRX-2 and -5 [31]. GRX-1 regulates transcription factors such as nuclear factor 1 (NF1) [32], nuclear factor- $\kappa \mathrm{B}(\mathrm{NF}-\kappa \mathrm{B})$ [33], and activator protein-1 (AP-1) [34]. These findings indicate that GRX could be one of the defense systems maintaining homeostasis and considered as a therapeutic target for various diseases via the control of oxidative signaling pathways [35].

ROS and NO are produced in LPS- or IL-1 $\beta$-stimulated articular chondrocytes, which possess NADPH oxidase [22, 36, 37]. In particular, strongly reactive NO can react easily with superoxide and subsequently form potent derivatives, including peroxynitrite, hydroxyl radical, and nitrogen dioxide, leading to catabolic responses in chondrocytes [36, 37]. Recently, GRX-1 was reported to be able to control the glutathionylation of molecules implicated in LPS- or IL-1 $\beta$-stimulated signaling pathways in a variety of cell types. GRX1 suppresses oxidative stress-induced AKT glutathionylation and apoptosis in human retinal pigment epithelial cells [38]. It also regulates IL-1-mediated glutathionylation of TNF receptor-associated factor 6, an intermediate molecule involved in the IL-1R and TLR4 signaling pathways [39]. In addition, microvascular endothelial cells and microphages from GRX-1-deficient mice showed enhanced LPS-stimulated glutathionylation of eNOS and, in a model of necrotizing enterocolitis (NEC), GRX-1-deficient mice were more susceptible to NEC development through the activation of TLR4 than the wild type [40]. In contrast, adenoviral overexpression of GRX-1 increased microglia activation and subsequently led to death of neuron cells [41]. GRX-1-deficient mice did not display increased vulnerability to acute injury of heart and lungs in ischemia/reperfusion and hyperoxia mouse model, whereas mouse embryonic fibroblasts from GRX-1-deficient mice were more tolerant to apoptosis induced by TNF- $\alpha$ plus actinomycin D. These findings suggest that variations in GRX-1 function may exist depending on cell types and animal models of disease [42]. 
An increased level of NO was found in human OA cartilage and human synovial fluid from rheumatoid arthritis and OA patients, suggesting that iNOS expression and the subsequent upregulation of NO are involved in the pathogenesis of arthritis [43-45]. Several lines of evidence demonstrated that NO suppressed the production of proteoglycans and collagen in rabbit cartilage and human chondrocytes $[46,47]$. In addition, inflammatory cytokines led to the expression of cartilage-degrading enzymes such as MMPs by inducing NO production $[48,49]$. In another study, iNOS inhibitors were shown to reduce cartilage degradation in an OA dog model and led to the suppression of IL-1 $\beta$-stimulated MMP production as well as the recovery of IL-1 $\beta$-inhibited glycosaminoglycan synthesis [36]. This accumulating evidence suggests that NO could be a target for OA therapy. We conclude that PEP-1-GRX-1 prevented LPS- and IL-1 $\beta$-associated inflammation in chondrocytes by modulating NO production and the MAPK and NF- $\kappa B$ signaling pathways.

Several therapeutic strategies that suppress OA have been developed, but many obstacles were revealed prior to their clinical applications due to difficulties in the delivery of drugs to chondrocytes embedded deep within a dense cartilage matrix. Subsequently, various approaches for circumventing these obstacles were suggested. Oligonucleotidebased gene therapy has been employed for the treatment of various inflammatory diseases [50]. In practice, this approach required additional components, including cationic lipids, polymers, and nanoparticles, to increase cellular uptake across the cell membrane and prevent degradation by nucleases [51], but toxicity-related problems subsequently appeared as an obstacle to the usage of drugs. In recent years, growing interest has developed in the use of PTD for the treatment of a variety of diseases, including OA. For example, in terms of apoptosis regulation, anti-cell death protein FNK fused with PTD was reported to protect against chondrocyte death and to suppress graft degeneration [52-54]. Tat-Bcl-XL and TatBH4, homology region 4 domain from Bcl-2/Bcl-XL, suppressed apoptosis by inhibiting the activation of caspase in human islets [55]. In addition, intranasal treatment with Tathuman acidic fibroblast growth factor (Tat-haFGF) significantly suppressed amyloid protein deposition in the mouse brain and the apoptosis of neurons in a mouse model of Alzheimer's disease, showing that Tat-haFGF can attenuate AD progression [56]. Although many factors, including the type of PTD, cargo molecules, and cell types, were employed differently in the above-mentioned experiments, these results illustrate the potential of using PTD fusion proteins for therapeutic purposes. The potential advantages of protein transduction technology include the application of targeted intracellular functions of particular signaling pathways, direct regulation of protein levels inside cells, and reversibility with minimal toxicity [57].

In conclusion, we have demonstrated that PEP-1-GRX-1, a fusion protein of GRX-1 with PTD, had the potential to penetrate chondrocytes and cartilage tissue compared with GRX-1 and protected chondrocytes from LPS- and IL-1 $\beta$-induced catabolic responses by suppressing the MAPK and NF- $\kappa B$ signaling pathways. In a mouse model of carrageenan-induced paw edema, PEP-1-GRX-1 suppressed the expression of MMP-13 significantly. Therefore, PEP-1GRX-1 may have beneficial effects for managing the pathogenesis of OA.

\section{Acknowledgements}

This work was supported by the grant (HI14C2248 and HI15C2699) from the Korean Health Technology R and D Project, Ministry of Health \& Welfare, Republic of Korea, and in part by Hallym University Research Fund.

\section{Disclosure Statement}

The authors declare no conflict of interest. 


\section{Cellular Physiology Cell Physiol Biochem 2017;41:252-264 \begin{tabular}{ll|l} 
DOI: 10.1159/000456090 & Ond Biochemistry & $\begin{array}{l}\text { 2017 The Author(s). Published by S. Karger AG, Basel } \\
\text { www.karger.com/cpb }\end{array}$ \\
\hline
\end{tabular}}

\section{References}

1 Taylor SE, Smeriglio P, Dhulipala L, Rath M, Bhutani N: A global increase in 5-hydroxymethylcytosine levels marks osteoarthritic chondrocytes. Arthritis Rheumatol 2014;66:90-100.

2 Weng T, Yi L, Huang J, Luo F, Wen X, Du X, Chen Q, Deng C, Chen D, Chen L: Genetic inhibition of fibroblast growth factor receptor 1 in knee cartilage attenuates the degeneration of articular cartilage in adult mice. Arthritis Rheum 2012;64:3982-3992.

-3 Chen LX, Lin L, Wang HJ, Wei XL, Fu X, Zhang JY, Yu CL: Suppression of early experimental osteoarthritis by in vivo delivery of the adenoviral vector-mediated nf-kappabp65-specific sirna. Osteoarthritis Cartilage 2008;16:174-184.

-4 Chen SY, Shiau AL, Li YT, Lin YS, Lee CH, Wu CL, Wang CR: Suppression of collagen-induced arthritis by intra-articular lentiviral vector-mediated delivery of toll-like receptor 7 short hairpin rna gene. Gene Ther 2012;19:752-760.

-5 Ditto AJ, Shah PN, Yun YH: Non-viral gene delivery using nanoparticles. Expert Opin Drug Deliv 2009;6:1149-1160.

6 Bottini M, Bhattacharya K, Fadeel B, Magrini A, Bottini N, Rosato N: Nanodrugs to target articular cartilage: An emerging platform for osteoarthritis therapy. Nanomedicine 2016;12:255-268.

7 Cucchiarini M, McNulty AL, Mauck RL, Setton LA, Guilak F, Madry H: Advances in combining gene therapy with cell and tissue engineering-based approaches to enhance healing of the meniscus. Osteoarthritis Cartilage 2016;24:1330-1339.

8 Ma M, Nath A: Molecular determinants for cellular uptake of tat protein of human immunodeficiency virus type 1 in brain cells. J Virol 1997;71:2495-2499.

-9 Vives E, Brodin P, Lebleu B: A truncated hiv-1 tat protein basic domain rapidly translocates through the plasma membrane and accumulates in the cell nucleus. J Biol Chem 1997;272:16010-16017.

10 Asoh S, Ohsawa I, Mori T, Katsura K, Hiraide T, Katayama Y, Kimura M, Ozaki D, Yamagata K, Ohta S: Protection against ischemic brain injury by protein therapeutics. Proc Natl Acad Sci U S A 2002;99:1710717112.

-11 Gros E, Deshayes S, Morris MC, Aldrian-Herrada G, Depollier J, Heitz F, Divita G: A non-covalent peptidebased strategy for protein and peptide nucleic acid transduction. Biochim Biophys Acta 2006;1758:384393.

12 Hwang HS, Park IY, Kim DW, Choi SY, Jung YO, Kim HA: Pep-1-fk506bp12 inhibits matrix metalloproteinase expression in human articular chondrocytes and in a mouse carrageenan-induced arthritis model. BMB Rep 2015;48:407-412.

13 Kim HA, Kim DW, Park J, Choi SY: Transduction of cu, zn-superoxide dismutase mediated by an hiv-1 tat protein basic domain into human chondrocytes. Arthritis Res Ther 2006;8:R96.

14 Henrotin Y, Kurz B, Aigner T: Oxygen and reactive oxygen species in cartilage degradation: Friends or foes? Osteoarthritis Cartilage 2005;13:643-654.

-15 Altay MA, Erturk C, Bilge A, Yapti M, Levent A, Aksoy N: Evaluation of prolidase activity and oxidative status in patients with knee osteoarthritis: Relationships with radiographic severity and clinical parameters. Rheumatol Int 2015;35:1725-1731.

16 Altindag O, Erel O, Aksoy N, Selek S, Celik H, Karaoglanoglu M: Increased oxidative stress and its relation with collagen metabolism in knee osteoarthritis. Rheumatol Int 2007;27:339-344.

$\checkmark 17$ Erturk C, Altay MA, Selek S, Kocyigit A: Paraoxonase-1 activity and oxidative status in patients with knee osteoarthritis and their relationship with radiological and clinical parameters. Scand J Clin Lab Invest 2012;72:433-439.

18 Kurz B, Jost B, Schunke M: Dietary vitamins and selenium diminish the development of mechanically induced osteoarthritis and increase the expression of antioxidative enzymes in the knee joint of str/1n mice. Osteoarthritis Cartilage 2002;10:119-126.

19 Zahedi Avval F, Holmgren A: Molecular mechanisms of thioredoxin and glutaredoxin as hydrogen donors for mammalian s phase ribonucleotide reductase. J Biol Chem 2009;284:8233-8240.

20 Hou C, Meng F, Zhang Z, Kang Y, Chen W, Huang G, Fu M, Sheng P, Liao W: The role of microrna-381 in chondrogenesis and interleukin-1-beta induced chondrocyte responses. Cell Physiol Biochem 2015;36:1753-1766. 


\section{Cellular Physiology Cell Physiol Biochem 2017;41:252-264 \begin{tabular}{c|c|c|} 
DOI: 10.1159/000456090 & C 2017 The Author(s). Published by S. Karger AG, Basel \\
www.karger.com/cpb
\end{tabular}

21 Park SJ, Cheon EJ, Lee MH, Kim HA: Microrna-127-5p regulates matrix metalloproteinase 13 expression and interleukin-1beta-induced catabolic effects in human chondrocytes. Arthritis Rheum 2013;65:31413152.

22 Aktan F: Inos-mediated nitric oxide production and its regulation. Life Sci 2004;75:639-653.

-23 Chen WP, Xiong Y, Hu PF, Bao JP, Wu LD: Baicalein inhibits mmps expression via a mapk-dependent mechanism in chondrocytes. Cell Physiol Biochem 2015;36:325-333.

-24 Clancy RM, Gomez PF, Abramson SB: Nitric oxide sustains nuclear factor kappab activation in cytokinestimulated chondrocytes. Osteoarthritis Cartilage 2004;12:552-558.

-25 Du G, Song Y, Wei L, Li L, Wang X, Xu Q, Zhan H, Cao Y, Zheng Y, Ding D: Osthole inhibits proliferation and induces catabolism in rat chondrocytes and cartilage tissue. Cell Physiol Biochem 2015;36:2480-2493.

-26 Sylvester J, El Mabrouk M, Ahmad R, Chaudry A, Zafarullah M: Interleukin-1 induction of aggrecanase gene expression in human articular chondrocytes is mediated by mitogen-activated protein kinases. Cell Physiol Biochem 2012;30:563-574.

27 Shelton MD, Mieyal JJ: Regulation by reversible s-glutathionylation: Molecular targets implicated in inflammatory diseases. Mol Cells 2008;25:332-346.

28 Okuda M, Inoue N, Azumi H, Seno T, Sumi Y, Hirata K, Kawashima S, Hayashi Y, Itoh H, Yodoi J, Yokoyama M: Expression of glutaredoxin in human coronary arteries: Its potential role in antioxidant protection against atherosclerosis. Arterioscler Thromb Vasc Biol 2001;21:1483-1487.

29 Reynaert NL, Wouters EF, Janssen-Heininger YM: Modulation of glutaredoxin-1 expression in a mouse model of allergic airway disease. Am J Respir Cell Mol Biol 2007;36:147-151.

30 Takashima Y, Hirota K, Nakamura H, Nakamura T, Akiyama K, Cheng FS, Maeda M, Yodoi J: Differential expression of glutaredoxin and thioredoxin during monocytic differentiation. Immunol Lett 1999;68:397401.

-31 Berndt C, Lillig CH, Holmgren A: Thiol-based mechanisms of the thioredoxin and glutaredoxin systems: Implications for diseases in the cardiovascular system. Am J Physiol Heart Circ Physiol 2007;292:H12271236.

-32 Bandyopadhyay S, Starke DW, Mieyal JJ, Gronostajski RM: Thioltransferase (glutaredoxin) reactivates the DNA-binding activity of oxidation-inactivated nuclear factor i. J Biol Chem 1998;273:392-397.

-33 Pineda-Molina E, Klatt P, Vazquez J, Marina A, Garcia de Lacoba M, Perez-Sala D, Lamas S: Glutathionylation of the p50 subunit of nf-kappab: A mechanism for redox-induced inhibition of DNA binding. Biochemistry 2001;40:14134-14142.

34 Hirota K, Matsui M, Murata M, Takashima Y, Cheng FS, Itoh T, Fukuda K, Yodoi J: Nucleoredoxin, glutaredoxin, and thioredoxin differentially regulate nf-kappab, ap-1, and creb activation in hek293 cells. Biochem Biophys Res Commun 2000;274:177-182.

- 35 Reynaert NL, van der Vliet A, Guala AS, McGovern T, Hristova M, Pantano C, Heintz NH, Heim J, Ho YS, Matthews DE, Wouters EF, Janssen-Heininger YM: Dynamic redox control of nf-kappab through glutaredoxin-regulated s-glutathionylation of inhibitory kappab kinase beta. Proc Natl Acad Sci U S A 2006;103:13086-13091.

-36 Mathy-Hartert M, Deby-Dupont GP, Reginster JY, Ayache N, Pujol JP, Henrotin YE: Regulation by reactive oxygen species of interleukin-1beta, nitric oxide and prostaglandin e(2) production by human chondrocytes. Osteoarthritis Cartilage 2002;10:547-555.

- 37 Stadler J, Stefanovic-Racic M, Billiar TR, Curran RD, McIntyre LA, Georgescu HI, Simmons RL, Evans CH: Articular chondrocytes synthesize nitric oxide in response to cytokines and lipopolysaccharide. J Immunol 1991;147:3915-3920.

38 Liu X, Jann J, Xavier C, Wu H: Glutaredoxin 1 (grx1) protects human retinal pigment epithelial cells from oxidative damage by preventing akt glutathionylation. Invest Ophthalmol Vis Sci;56:2821-2832.

- 39 Chantzoura E, Prinarakis E, Panagopoulos D, Mosialos G, Spyrou G: Glutaredoxin-1 regulates traf6 activation and the il-1 receptor/tlr4 signalling. Biochem Biophys Res Commun 2010;403:335-339.

40 Shang Q, Bao L, Guo H, Hao F, Luo Q Chen J, Guo C: Contribution of glutaredoxin-1 to s-glutathionylation of endothelial nitric oxide synthase for mesenteric nitric oxide generation in experimental necrotizing enterocolitis. Transl Res DOI:10.1016/j.trsl.2016.01.004.

-41 Miller OG, Behring JB, Siedlak SL, Jiang S, Matsui R, Bachschmid MM, Zhu X, Mieyal JJ: Upregulation of glutaredoxin-1 activates microglia and promotes neurodegeneration: Implications for parkinson's disease. Antioxid Redox Signal DOI:10.1089/ars.2015.6598. 


\section{Cellular Physiology Cell Physiol Biochem 2017;41:252-264 \begin{tabular}{ll|l} 
and Biochemistry $10.1159 / 000456090$ & $\begin{array}{l}\text { () 2017 The Author(s). Published by S. Karger AG, Basel } \\
\text { www.karger.com/cpb }\end{array}$
\end{tabular}}

Hwang et al.: MMP-13 and NO Expression Modulated by PEP-GRX-1

42 Ho YS, Xiong Y, Ho DS, Gao J, Chua BH, Pai H, Mieyal JJ: Targeted disruption of the glutaredoxin 1 gene does not sensitize adult mice to tissue injury induced by ischemia/reperfusion and hyperoxia. Free Radic Biol Med 2007;43:1299-1312.

43 Amin AR, Di Cesare PE, Vyas P, Attur M, Tzeng E, Billiar TR, Stuchin SA, Abramson SB: The expression and regulation of nitric oxide synthase in human osteoarthritis-affected chondrocytes: Evidence for upregulated neuronal nitric oxide synthase. J Exp Med 1995;182:2097-2102.

-44 Farrell AJ, Blake DR, Palmer RM, Moncada S: Increased concentrations of nitrite in synovial fluid and serum samples suggest increased nitric oxide synthesis in rheumatic diseases. Ann Rheum Dis 1992;51:12191222.

45 Karan A, Karan MA, Vural P, Erten N, Tascioglu C, Aksoy C, Canbaz M, Oncel A: Synovial fluid nitric oxide levels in patients with knee osteoarthritis. Clin Rheumatol 2003;22:397-399.

46 Hauselmann HJ, Stefanovic-Racic M, Michel BA, Evans CH: Differences in nitric oxide production by superficial and deep human articular chondrocytes: Implications for proteoglycan turnover in inflammatory joint diseases. J Immunol 1998;160:1444-1448.

47 Taskiran D, Stefanovic-Racic M, Georgescu H, Evans C: Nitric oxide mediates suppression of cartilage proteoglycan synthesis by interleukin-1. Biochem Biophys Res Commun 1994;200:142-148.

-48 Otero M, Gomez Reino JJ, Gualillo O: Synergistic induction of nitric oxide synthase type ii: In vitro effect of leptin and interferon-gamma in human chondrocytes and atdc5 chondrogenic cells. Arthritis Rheum 2003;48:404-409.

49 Sasaki K, Hattori T, Fujisawa T, Takahashi K, Inoue H, Takigawa M: Nitric oxide mediates interleukin-1induced gene expression of matrix metalloproteinases and basic fibroblast growth factor in cultured rabbit articular chondrocytes. J Biochem 1998;123:431-439.

-50 Somasuntharam I, Yehl K, Carroll SL, Maxwell JT, Martinez MD, Che PL, Brown ME, Salaita K, Davis ME: Knockdown of tnf-alpha by dnazyme gold nanoparticles as an anti-inflammatory therapy for myocardial infarction. Biomaterials 2016;83:12-22.

51 Lv H, Zhang S, Wang B, Cui S, Yan J: Toxicity of cationic lipids and cationic polymers in gene delivery. J Control Release 2006;114:100-109.

52 Nakachi N, Asoh S, Watanabe N, Mori T, Matsushita T, Takai S, Ohta S: Transduction of anti-cell death protein fnk suppresses graft degeneration after autologous cylindrical osteochondral transplantation. J Histochem Cytochem 2009;57:197-206.

53 Ozaki D, Sudo K, Asoh S, Yamagata K, Ito H, Ohta S: Transduction of anti-apoptotic proteins into chondrocytes in cartilage slice culture. Biochem Biophys Res Commun 2004;313:522-527.

-54 Sudo K, Asoh S, Ohsawa I, Ozaki D, Yamagata K, Ito H, Ohta S: The anti-cell death fnk protein protects cells from death induced by freezing and thawing. Biochem Biophys Res Commun 2005;330:850-856.

-55 Klein D, Ribeiro MM, Mendoza V, Jayaraman S, Kenyon NS, Pileggi A, Molano RD, Inverardi L, Ricordi C, Pastori RL: Delivery of bcl-xl or its bh4 domain by protein transduction inhibits apoptosis in human islets. Biochem Biophys Res Commun 2004;323:473-478.

-56 Lou G, Zhang Q, Xiao F, Xiang Q, Su Z, Zhang L, Yang P, Yang Y, Zheng Q, Huang Y: Intranasal administration of tat-hafgf((1)(4)(-)(1)(5)(4)) attenuates disease progression in a mouse model of alzheimer's disease. Neuroscience 2012;223:225-237.

57 Kabouridis PS, Hasan M, Newson J, Gilroy DW, Lawrence T: Inhibition of nf-kappa b activity by a membrane-transducing mutant of i kappa b alpha. J Immunol 2002;169:2587-2593. 